\title{
中炭素鋼におけるセメンタイト球状化挙動の 電子顕微鏡によるその場観察

\section{In-situ TEM Observation of Spheroidization Behavior of Cementite in Medium Carbon Steels}

Yutaka KAnETSUKI, Keiichi Yasunaga and Hirotaro MoRI

\section{Synopsis :}

The spheroidization treatment for medium carbon steels has been usually performed by annealing just above $A_{1}$ temperature and slow cooling.

In this study, the spheroidization behavior of cementites in the steel was in-situ observed by ultra-high voltage electron microscopy, in order to investigate the effect of initial microstructure on the spheroidization behavior. Two microstructures, i. e. fine ferrite-pearlite and bainite, were selected as the initial microstructure for the treatment, and were prepared by thermo-mechanical treatments.

By continuous observation, following results were obtained. Re-austenitization occured at colony and grain boundaries in ferrite-pearlite structure. In the case of bainite, it occured in the vicinity of small cementite particle which distributed homogeneously in ferrite grain. Furthermore, substructures were formed by re-arrangement of dislocations.

During cooling, coalescence of austenite grains occured. Based upon the observation of this behavior, discussion was focused on the role of internal stress caused by eigen strain due to transformation.

Key words : medium carbon steel; intercritical annealing; spheroidization; re-austenitization; high voltage electron microscopy.

\section{1. 緒言}

機械部品の多くは熱間, もしくは冷間で鍛造により成 形される。このうち冷間鍛造は熱間鍛造に比較し歩留 り，精度に優れておりますます多く適用されてきてい る. 冷間鍛造を機械構造用鋼である中若素鋼に適用する にあたりこれまでセメンタイトの球状化焼鈍が行われ てきた。しかしながら，この球状化処理は長時間の熱処 理時間を要しそのため短時閏での処理を可能にする素材 が望まれてきている.

普通鋼では制御压:延，制御冷却により微細フェライ ト・パーライト組織にすることにより, 球状化処理時間 を簡略化した場令でも再生パーライトは生成せず良好な 球状化組織が得られることを既に報告している1). 一 方，焼入性の良い低合金鋼では压延後の通常の空冷にお
いても, 組織はベイナイトが混在, もしくは主体とな る. ベイナイト組織を球状化処理した場合，炭化物の形 状は良好な球状となるものの, 微細に分散するため硬さ の低下は小さく2), そのためべイナイト組織においては 炭化物の粗大化を促進することがのぞまれる.

球状化処理の方法には変態点直下の焼鈍によるものと 二相域に加熱後さらに徐冷する方法の二つがある．後者 の方法は一部オーステナイト化する反応を経て球状化す る方法であり, 中炭素鋼では多くこの方法が用いられて いる. ところで球状化挙動に関するこれまでの研究はほ とんどが球状化処理前後の組織観祭によるもので, 組織 の具体的な役割について詳細は不明である。またこれま での報告は焼準処理後の組織であるフェライト・パーラ イト組織についてなされたもので, ベイナイト組織に関 しては詳細に検討されていない.

平成 3 年 10 月本会講演大会にて発表 平成 3 年 7 月 10 日受付 (Received July 10, 1991)

* (株)神厂製銅所鉄鎆技術研究所 工博（Iron \& Steel Research Laboratories, Kobe Steel Works, 1-3-18

Wakinohama-cho Chuo-ku Kobe 651)

*2 (株)神正製鎆所神戸製鉄所 (Kobe Works, Kobe Steel Works)

*3 大阪大学超高庄電子顕微鏡センター L博 (Research Center for Ultra-High Voltage Electron Microscopy, Osaka University) 
一力，二相域に扫けるオーステナイトへの逆変態に関

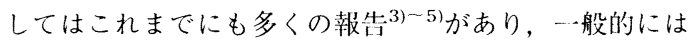
加熱後クェンチを行い観察するカ法がとられている. し かしながら，二相域からの変態挙動はオーステナイト域 からの通常の変態挙動に比べ大きく変化することが知ら れて抢り ${ }^{6)}$, 果たしてクェンチによって組織を正確に凍 結できるか否かは疑問である。したがって，組織变化を 正確に把握するためには変態のその場観察を行うことが ぜひとも必要となる。超高压電子顕微鏡法はこの目的に 対しても最も有効な手段であり、本研究ではフェライト・ パーライト組織抢よびベイナイト組織の球状化挙動の比 較を超高压電子顕微鏡を用いたその場観察により検討す ることを目的とした．

\section{2. 実 験 方 法}

用いた供試鋼は典型的な中炭素低合金鋼 SCM435 で Table 1 にその化学成分を示す.中岑素鋼 S45C は一部 子備検討にもちいた。

電子顕微鏡では観察可能な而積は限定される。そのた め組織変化を観察するための結晶粒径も観察視野の大き さに比べ十分に微細化する必要がある. Fig. 1 は組織の
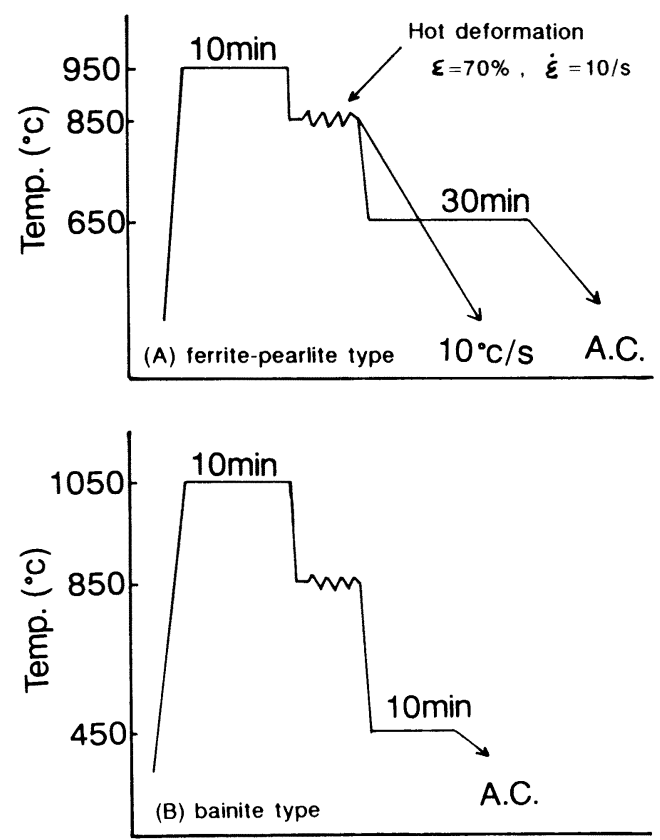

Time

Fig. 1. Schematic illustration of thermo-mechanical treatment. (A) and (B) were applied for formation of fine ferrite-pearlite and bainite microstructure, respectively.
Table 1. Chemical compositions of steels used (mass $\%)$.

\begin{tabular}{l|cccccccc}
\hline & $\mathrm{C}$ & $\mathrm{Si}$ & $\mathrm{Mn}$ & $\mathrm{P}$ & $\mathrm{S}$ & $\mathrm{Ni}$ & $\mathrm{Cr}$ & $\mathrm{Mo}$ \\
\hline $\mathrm{SCM} 435$ & 0.35 & 0.18 & 0.78 & 0.016 & 0.016 & 0.02 & 1.08 & 0.16 \\
$\mathrm{~S} 45 \mathrm{C}$ & 0.45 & 0.21 & 0.71 & 0.020 & 0.013 & - & 0.12 & - \\
\hline
\end{tabular}

微細化のために用いた熱䦌加たシミュレーターによる加 工熱処理のパターンを示している。試験片形状は直径 8 $\mathrm{mm}$, 高さ $12 \mathrm{~mm}$ とし区:延棒鋼より機械加深よより製作 した．熱間加」条件は微細なオーステナイトの得られる 条件で，詳細は S45C，SCM435 についてそれぞれ別 報12)に示しているが，熱開加1にによりオーステナイト 粒を微細化し，その後次に亦すように制御冷却もしくは 急冷恒温保持により組織調整を行った。

ここでは前組織の影響を検㗅するため，SCM435を 用い闰一組成でフェライト・パーライト組織抢よびベイ ナイト組織に調整した。すなわち，Fig. 1 に示すように 熱間加:後, それぞれ $650^{\circ} \mathrm{C}$ および $450^{\circ} \mathrm{C}$ で惟温変態 により作成した．急冷怕温変態は熱㨽加厂，後の静的再結 晶による組織の粗大化の防止が目的である。

電子顕微鏡観祭のための試料は、1:述の処理後, 縦断面 中央部から採取し電解研磨により薄膜を作成した．Fig. 2 は電子顕微鏡内で加熱した時の温度パターンを示して いる，加熱，冷却速度の調整は陚料近傍に設置したヒー ターの電力調整を階段状にすることによって行った，最 高加熱温度は薄膜のため組織の粗大化を防ぐ目的で, $A_{1}$ 点である $740^{\circ} \mathrm{C}$ とした。冷却速度は $20 \sim 30^{\circ} \mathrm{C} / \mathrm{h}$ に 対応する，組織変化は連級的にビデオ撖影し，また途中

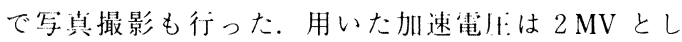

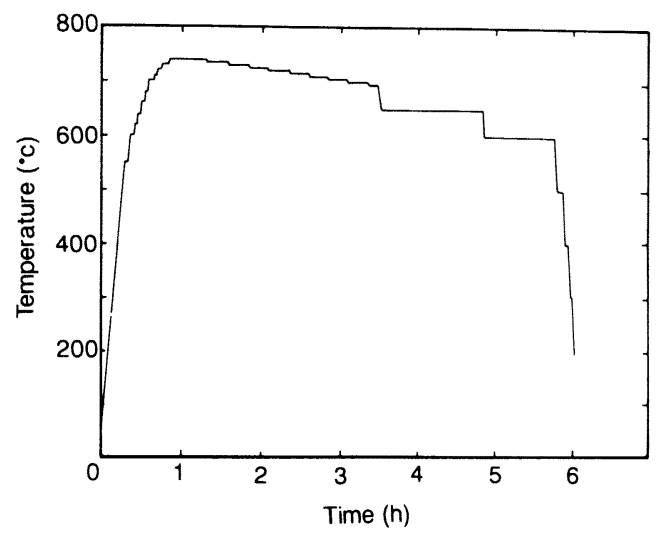

Fig. 2. Heat pattern applied for in-situ observation of spheroidization behavior by ultra-high voltage electron microscopy. 
た。また，薄膜での反応とバルクでの反応の予備検討と しての比較を次のように行った。前組織はこれまでにも 報告 ${ }^{4)}$ あるフェライト・パーライト組織とし, S45C を 用い熱間加工後 $10^{\circ} \mathrm{C} / \mathrm{s}$ の連続冷却で微細組織を作成 し，加工熱処理を施した後さらに $740^{\circ} \mathrm{C} に$ 加熱直後に 水冷により組織を凍結した. 電顕観察は水冷後薄膜を作 製する従来の方法により行った。

\section{3. 実 験 結 果}

\section{$3 \cdot 1$ フェライト・パーライト組織 (S45C) の二相域から 水冷した場合の組織変化}

Photo. 1 は (A) に微細フェライト・パーライト組織 をまま（B）にさらに $740^{\circ} \mathrm{C} に$ 加熱直後に水冷した場 合のバルクでの組織変化を示している。（B）において フェライト・パーライト界面にマルテンサイト組織（矢

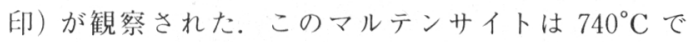
オーステナイト相であったことを示すもので, 粒界で オーステナイトへ逆変態したことを，また界面に打いて は粒内に比べオーステナイト化が非常に速く起こること
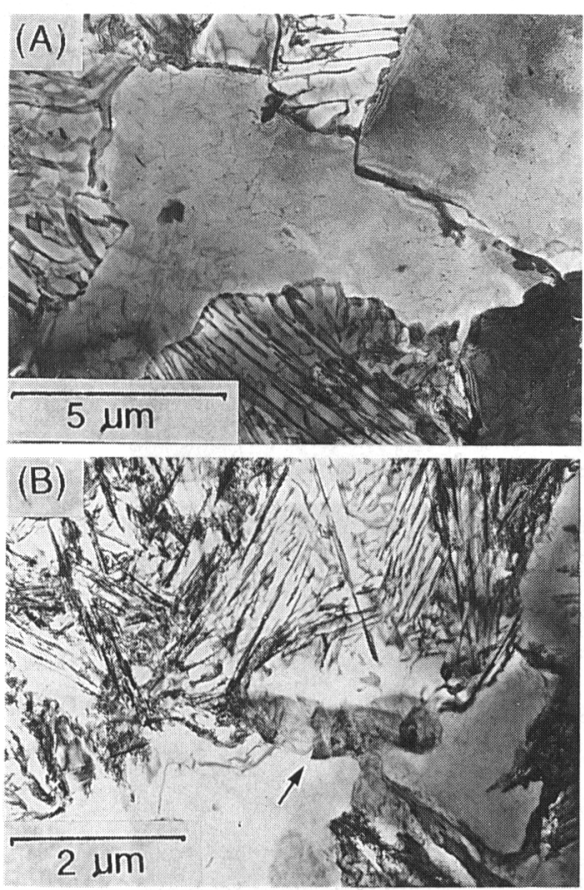

Photo. 1. TEM micrographs of the ferrite-pearlite microstructure (A) and the change caused by water-quenching after heating up to $740^{\circ} \mathrm{C}(\mathrm{B})$. The martensite located at boundaries indicates the rapid re-austenitization.
を示唆している. そこで, 次に薄膜でのこの反応の再現 の可能性について直接観察した結果と比較した。さらに 本研究の目的である前組織の影響の比較検討のため次に 述べる直接観察には同一組成で微細なフェライト・パー ライトおよびベイナイト組織の得られる SCM435を用 いた。

\section{$3 \cdot 2$ フェライト・パーライト組織 (SCM435) の組織变化 の直接観察結果}

Photo. 2 は加熱, 冷却過程でのフェライト・パーライ ト組織の変化を示すもので，(A）は加熱前の組織を （D）は冷却後の組織を (B) (C) は $675^{\circ} \mathrm{C}, 730^{\circ} \mathrm{C}$ での 観察結果で場所は異なるが代表的な組織である。電顕内 での加熱，冷却によってセメンタイトが球状化されてい ることが (D) で確認され，本実験で用いた熱処理パ ターンで, かつ電顕内で球状化処理のシミュレーション が可能であるかがわかった。また，(B)(C) では $3 \cdot 1$ で 述べたように，セメンタイトの再固溶によるオーステナ イトへの逆変態が粒界で起こり，オーステナイト粒が粒 界に生成することが確認された。次に場所を限定し反応 の様子を連続観察した結果を次に述べる.

Photo. 3 は反応の過程を同一の場所で連続観察した 結果の一例を示している.オーステナイトはフェライ ト・パーライト界面 (矢印 A) 拈よびパーライトコロニー 界面 (矢印 B) に拈いてパーライト中の層状セメンタイ トの端から固溶することにより形成され，それらが合体 することにより成長することがわかる．Photo. 1 に示 した S45Cの水冷した試料の観察結果に認められた反 応が粒界で起こる様子が確認された。また，連続観察の 結果セメンタイトの変化が $A_{1}$ 点よりも低い約 $600^{\circ} \mathrm{C}$ で既に起こることがわかった。これまでの報告では例え ば，YANG ら ${ }^{4)}$ は界面でオーステナイト化する同様の反 応を変態点直上で確認している。しかし本実験のように 変態点の前後を連続的に観察した例はなく，反応開始温 度を明らかにした例は見あたらない。さらにY YANGらは 焼もどし材を用いており，本実験材のように動的再結晶 後に急冷した場合とは異なっている。したがって，逆変 態反応が非平衡状態で変態したことにより促進される可 能性を示していると考えられる7)が，この点は今後検討 を要する。

Photo. 4 はフェライト・オーステナイト組織の泠却中 の変化を示すもので，(A) および（B）は，それぞれ同 一場所の $710^{\circ} \mathrm{C}, 670^{\circ} \mathrm{C}$ での観察結果である。オーステ ナイト結晶粒の位置が相対的に变移していることが両者 の比較からわかった。また, Photo. 4 (A) に矢印で示 す微細粒は $670^{\circ} \mathrm{C}$ では認められず，大きく移動合体し 

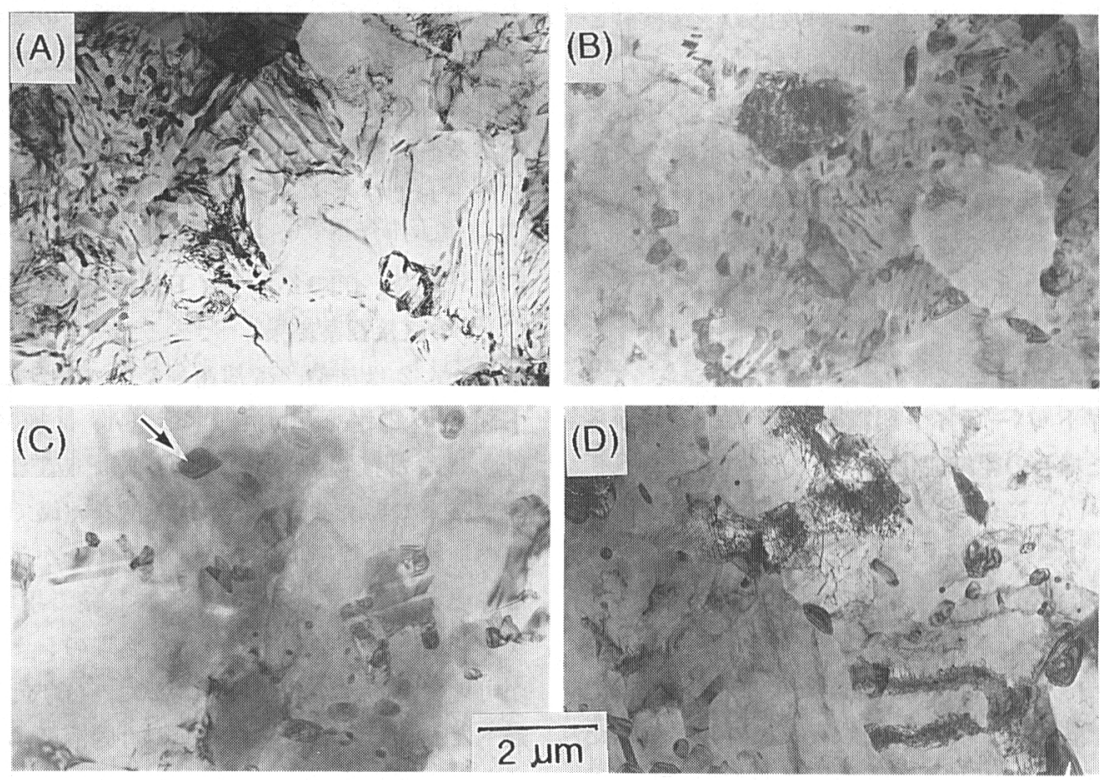

(A) and (D) show the initial and final microstructure

(B) and (C) were taken at $675^{\circ} \mathrm{C}$ and $730^{\circ} \mathrm{C}$, respectively

An example of austenite grain is indicated by arrow

Photo. 2. TEM micrographs depicting successive stages of spheroidization in SCM435 steel with a ferrite-pearlitic microstructure.
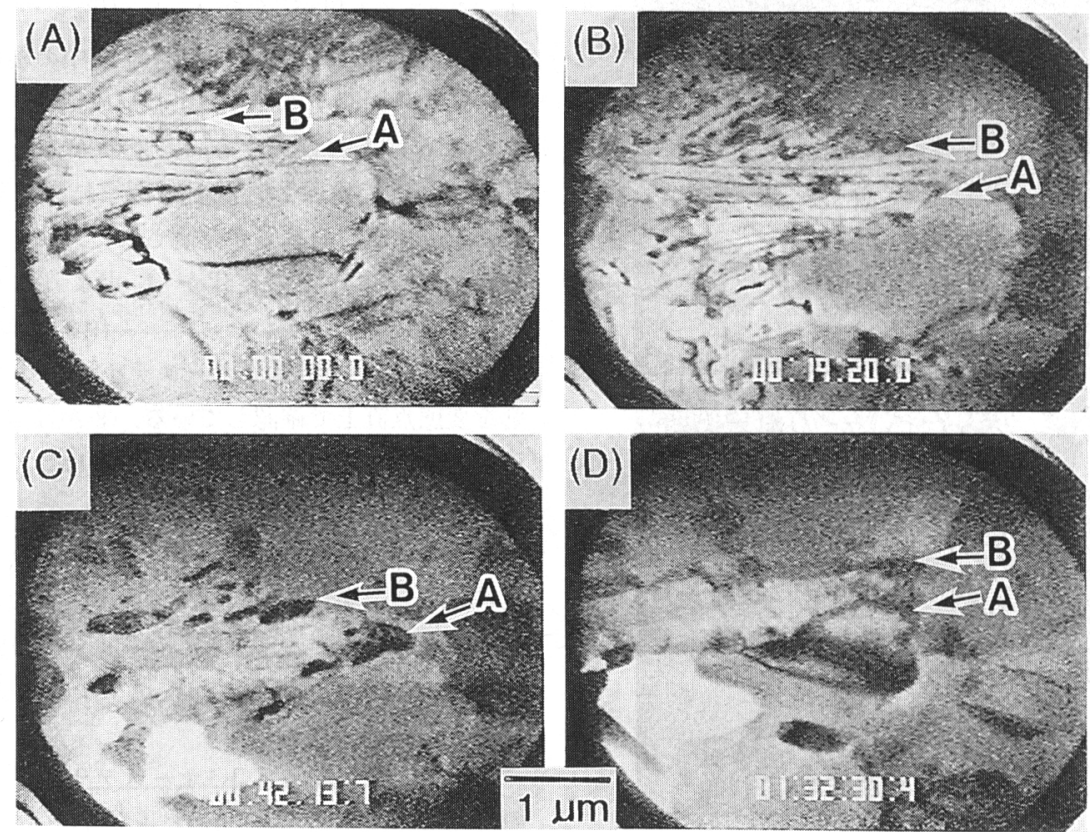

$\begin{array}{llll}\text { (A) Room temperature } & \text { (B) } 650^{\circ} \mathrm{C} & \text { (C) } 680^{\circ} \mathrm{C} & \text { (D) } 720^{\circ} \mathrm{C}\end{array}$

Ferrite-pearlite and colony boundary are indicated by arrow $\mathrm{A}$ and $\mathrm{B}$, respectively

Photo. 3. Continuous observation of the change in ferrite-pearlite microstructure during annealing. New austenite grains were formed at grain and colony boundaries and fragmentation of pearlitic cementite occurred in pearlite grains. 

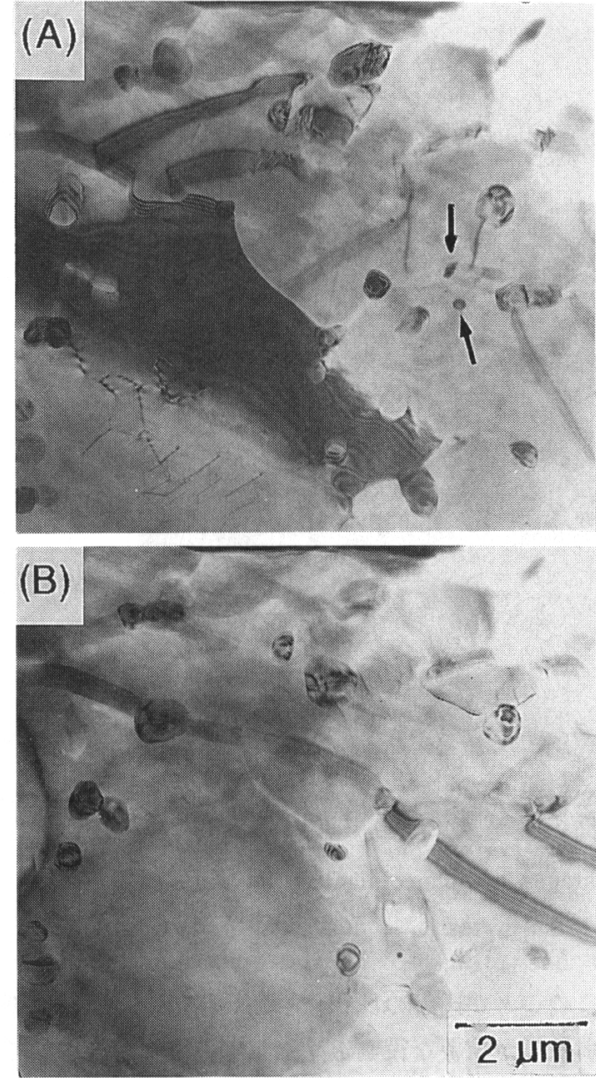

Photo. 4. TEM micrographs showing the microstructural change upon slow cooling at a fixed location. (A) and (B) were taken at $710^{\circ} \mathrm{C}$ and $690^{\circ} \mathrm{C}$, respectively.

たものと考えられる。このオーステナイト粒の移動合体 はフェライト粒界の移動により粒界に沿って起こったも のと考えられる.ささらに Photo. 4 (A) (B) の比較から わかるようにベンドコンター (Bend contour) は冷却中 に，また恒温保持中にも大きく移動することが観察され た。このことは応力状態が変化，または応力の発生を示 唆している. 応力は各部分における熱膨張係数の不均一 や, 冷却の不均一, 変態により発生するが, ここでは徐 冷であり，主として変態に起因するものと考えられる.

\section{$3 \cdot 3$ ベイナイト組織 (SCM435) の組織変化の直接観察 結果}

Photo. 5 はベイナイト組織の同一場所ではないが代 表的な変化を示すもので，（A）は加熱前を，(D) は冷 却後の組織であり，(B)(C) はそれぞれ $700^{\circ} \mathrm{C}, 600^{\circ} \mathrm{C}$ の冷却中の状態を示している. (A) (D) の比較から明ら かなように, 加熱前にベイナイトラスに沿って析出して
いた微細セメンタイトは球状セメンタイトに変化し,ま た, Photo. 6 に拡大した冷却後の組織を示している が, 球状セメンタイト (矢印 A) とフェライト・パーラ イト組織では認められなかった転位下部組織 (矢印 B) が認められる.この転位下部組織はPhoto. 5 (B) (C) に示すように逆変態中の組織においても認められる。冷 却後のセメンタイトは組織的に大きな変化がないことか ら生成したオーステナイト粒から凝縮生成したものと考 えられる。

転位下部組織の形成はフェライト・パーライト組織の 場合と比べ特徴的である。これらの反応を連続観察した 結果を次に示す.

Photo. 7 は加熱中の同一場所の変化を示したもの で, 加熱温度の上昇とともに，炭化物を含む微細な領域 で変化が起こる。この段階で微細なオーステナイト粒が 形成されていると考えられる. また，元のベイナイト中 には高密度の転位が存在しているが,これらの転位が再 配置により粒内にネットワーク状の転位下部組織( 矢 印）を形成することがわかる。この組織は Photo. 5 に 示すものと同じものである.

Photo. 8 には同一視野の同じ転位下部組織（矢印）に 注目し冷却中の变化の状況を観察した結果示している が，刻々とその位置と形態を不規則に変化させることが 認められた。

\section{4. 考察}

中炭素鋼を二相域に加熱，徐冷することによりセメン タイトを球状化する方法に関して，超高圧電顕内で組織 変化を再現することが可能であることがわかった．以下 に前組織をフェライト・パーライト組織とした場合の結 果とべイナイト組織とした場合の結果を比較検討する.

フェライト・パーライト組織については従来の報告に 示されているように8)，粒界に接したパーライト中の七 メンタイトが固溶することによりオーステナイト粒が形 成され，これらのオーステナイト粒が合体することによ り逆変態が進行すること，また泠却により逆変態オース テナイト粒から球状セメンタイトが形成されることが確 認された。

一方，ベイナイト組織についてはこれまでに報告され たものがなく，詳細は不明であったが，本実験の結果， 次のことがわかった。二相域の温度で形成されるオース テナイト粒はフェライト粒内において炭化物から形成さ れるが，その合体の速度はフェライト・パーライト組織 の場合と比較し著しく遅くほとんど進行しない。このよ うに遅い合体速度のため冷却後のセメンタイトは球状で 

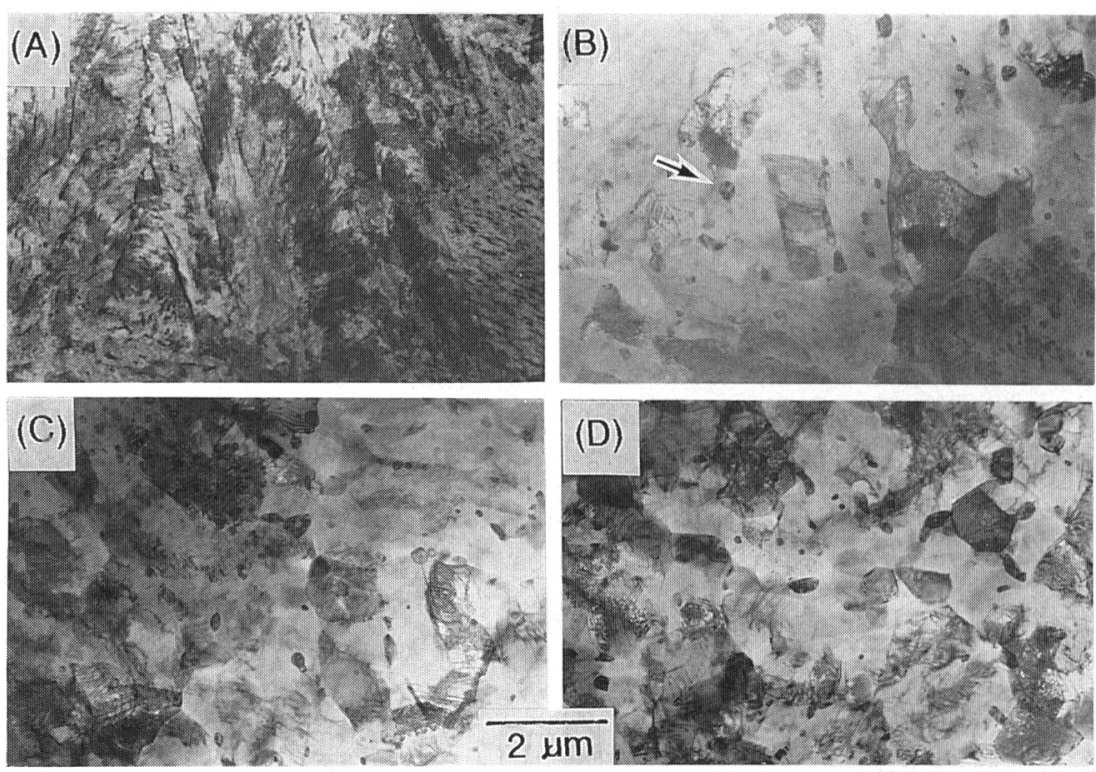

(A) and (D) show the initial and final microstructure
(B) and (C) were taken at $700^{\circ} \mathrm{C}$ and $600^{\circ} \mathrm{C}$, respectively
An example of austenite particle is indicated by arrow

Photo. 5. TEM micrographs showing successive stages of spheroidization in SCM435 steel with a bainitic microstructure.

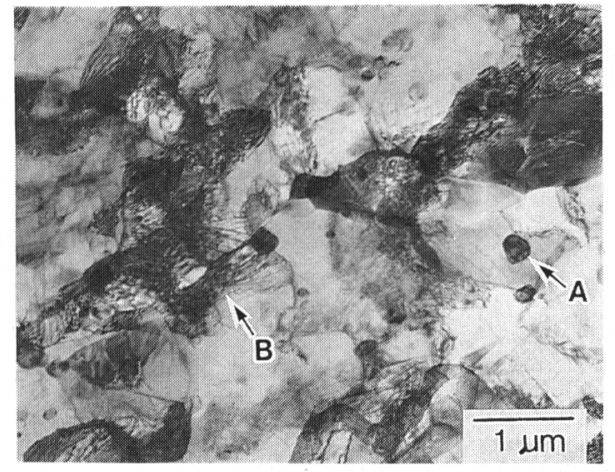

Photo. 6. TEM micrograph showing the typical example of spheroidized cementite particle (A) and dislocation substructure $(\mathrm{B})$ in the case of bainitic initial microstructure.

あるが微細なままで，硬度の低下の小さいこれまでの結 果をうらづけることがわかった.

上記の結果をオーステナイト粒の形成の過程で比較す ると,フェライト・パーライト組織に扔いてはパーライ ト中のセメンタイトの一端もしくは両端が大傾角粒界に 接していることが炭化物の固溶と拡散に重要な役割を果 たしている。一方べイナイト組織では微紻セメンタイト のほとんどはフェライト粒内にそれぞれが孤立して存在
し，このことが両者の球状化挙動の相違の基本的な原因 で，前組織が重要な役割を果たしていることを示してい る.

軟質化にはオーステナイト粒の合体，粗大化が重要な 過程であるが，連続観察により合体速度に変態に起因す る内部応力の不均一分布の寄与が大きいことも示唆され た. 本供試鋼の炭素量ではオーステナイトからフェライ ト・セメンタイトで約 $4 \%$ の体積変化が起こり，そのた めオーステナイト粒には固有歪みが発生する。一例とし て Photo. 2 (D) に一部認められるようにフェライト・ パーライト組織において冷却後の状態で局所的に新たに 転位組織が形成されておりここの転位組織は Y ANG らが $\alpha$-veining ${ }^{9)}$ との関連を示唆しているように，変態に関 与して形成される転位組織と考えられる. 内部応力はさ らに組織の再配列を促すが，フェライト・パーライト組 織ではベイナイト組織に比べマクロ的に組織が不均質で あることにより内部応力は比較的長範囲に及び粒界の移 動によって緩和されると考えられる。一方，ベイナイト ではオーステナイト粒も小さく比較的均質に分布してい るため内部応力も短範囲であること，さらに，もともと 存在していた粒内の転位はネットワーク状に再配置され るが，二相域でも安定に存在し，その移動により内部応 力が粒内で緩和され，オーステナイト粒の合体粗大化が 

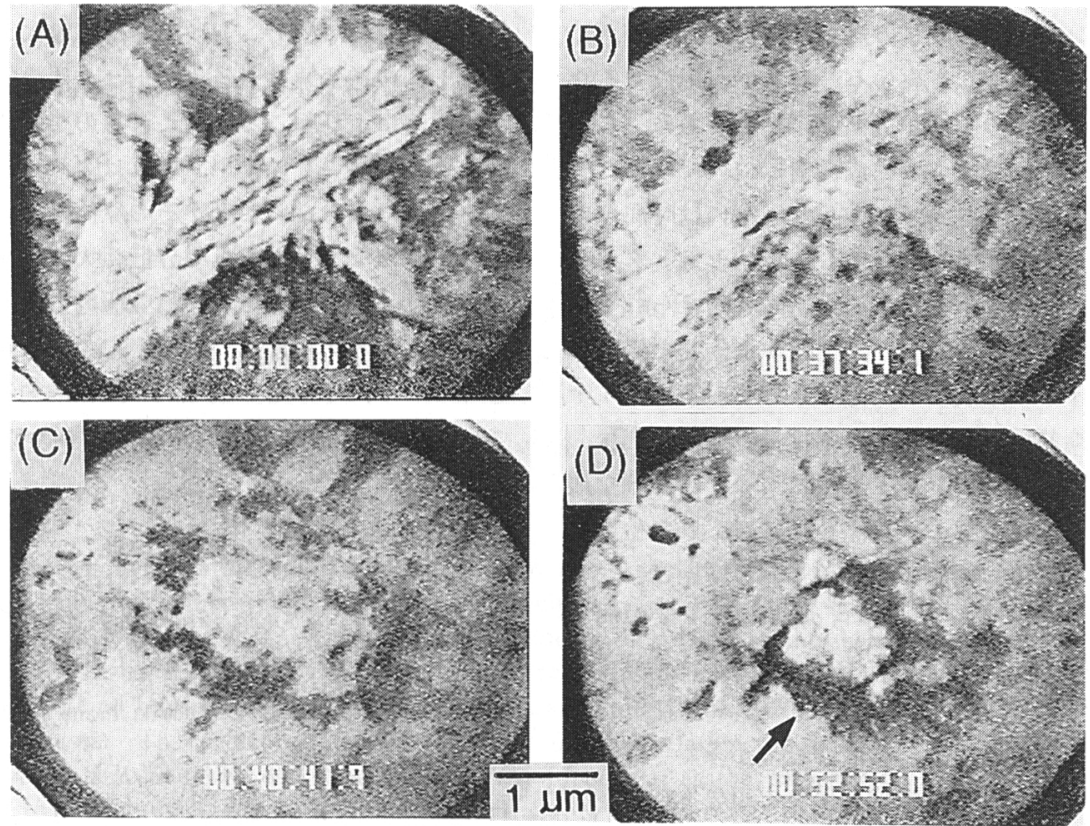

$\begin{array}{llll}\text { (A) Room temperature } & \text { (B) } 700^{\circ} \mathrm{C} & \text { (C) } 730^{\circ} \mathrm{C} & \text { (D) } 740^{\circ} \mathrm{C}\end{array}$

Photo. 7. Continuous observation of the change in bainite microstructure upon heating. Spheroidization of cementite and the formation of dislocation substructure were recognized.
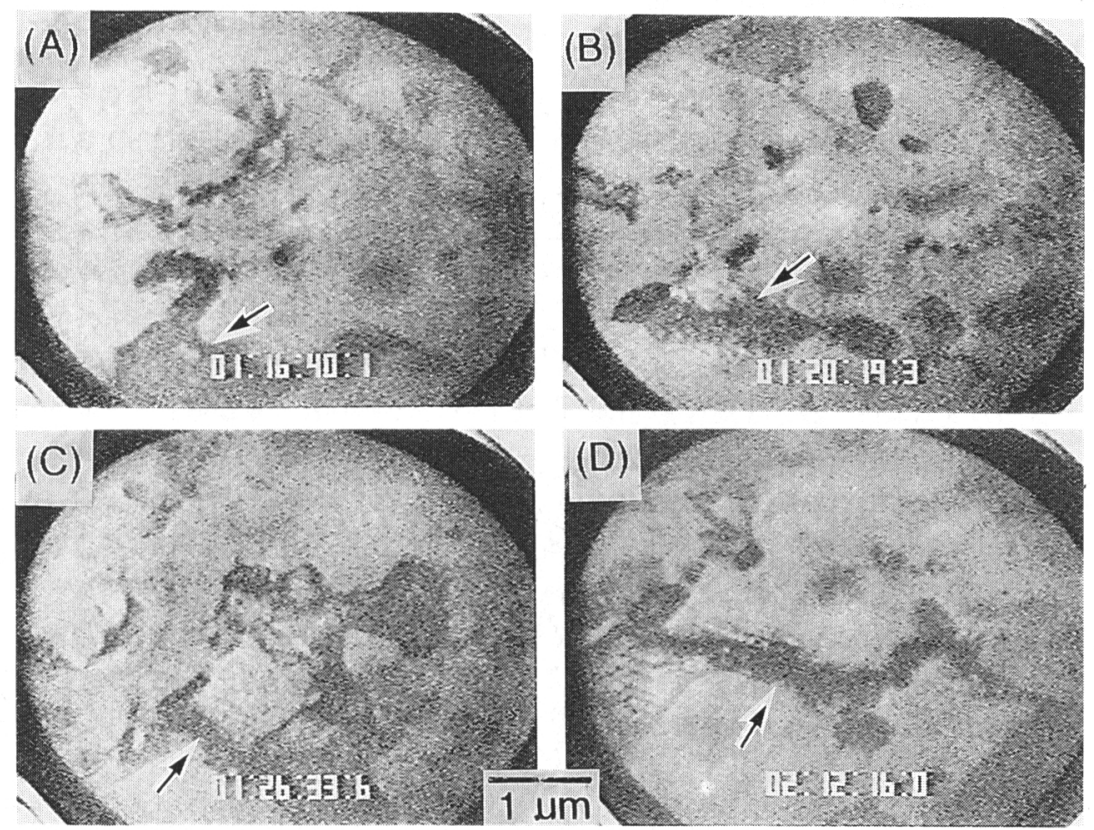

$\begin{array}{lll}\text { (A) } 740^{\circ} \mathrm{C} & \text { (B) and (C) } 735^{\circ} \mathrm{C} & \text { (D) } 720^{\circ} \mathrm{C}\end{array}$

Photo. 8. Continuous observation of the change in dislocation substructure during slow cooling stage. 
起こりにくい原因と考えられる.

次に, セメンタイトの成長の過程であるが, 通常, 球 状セメンタイトと共存して再生パーライトが生成するた め, 再生パーライトの制御が工業的に重要である. しか しながら，再生パーライトの生成機構についてはまだ不 明である。従来，七メンタイトの完全固溶には時間を要 するため微細セメンタイトが残留し, 球状セメンタイト はこの微細セメンタイトを核に成長すると考えられてい る.したがって，微細セメンタイト核が消失した場合に は再生パーライトが生成すると考えられている。ベイナ イト組織では冷却後のセメンタイトは良好な球状を呈し ており，本実験ではセメンタイト核についての詳細な観 察は行っていないが残存セメンタイトに対応して生成し たものと考えられる. 再生パーライトへの変態は, フェ ライト・オーステナイト界面からのパーライト変態で ある亜共析鋼と同様な状況と考えられるが，例えば THOMPSON らは, パーライト中のフェライトが初析フェ ライトと連続していること，界面に転位が多く生成して いるなど通常のパーライト変態と異なる現象を報告して おり ${ }^{10)}$ ，微細セメンタイト核の有無だけではなくセメ ンタイトの成長過程について詳細な検討がさらに必要と 考えられる.

\section{5. 結言}

フェライト・パーライト組織とベイナイト組織の球状 化挙動を超高圧電顕による直接観察により比較し, 次の 結果が得られた.

(1)フェライト・パーライト組織における逆変態は粒
界で起こり，このため速い速度で粗大オーステナイト粒 が形成される，一方，ベイナイト組織に打けるオーステ ナイトへの逆変態はベイナイトラス間の微細セメンタイ トの固溶により起こるが, これらの微細オーステナイト 粒の合体は起こりにくい。これは大傾角粒界に接した七 メンタイトが少ないことがその原因と考えられる.

(2)またセメンタイトの分散粗大化はオーステナイト 粒の移動，合体によるが，その駆動力として変態による 固有歪みが考えられる．固有応力の分布が合体速度に影 響しており，そのため組織的に比較的均質なべイナイト では粗大化が起こりにくいもう一つの原因と考えられ る.

\section{文献}

1 ）金築 裕, 勝亦正昭, 澤田裕治: 鉄と銅, 75 (1989), p. 1178

2 ) 粕谷 治, 安永恵一, 金築 裕: 材料とプロセス, 3 (1990), p. 1831

3 ) G. R. SPEICH and A. SzIRMAE: Trans. AIME, 245 (1969), p. 1063

4 ) D. Z. Yang, $E . L$. Brown, D. $K$. Matlock and $G$. Krauss: Metall. Trans. A, 16 (1985), p. 1523

5 ) E. Navara, B. Bengtsson and $K$. E. Easterling: Mater. Sci. Technol., 2 (1986), p. 1196

6 ) B. M. Bronfin, $M$. I. Goldshteyn, A. A. Yemelyanov and A. Z. Shifman: Phys. Met. Metall., 59 (1985), p. 129

7 ) 金築 裕, 勝亦正昭, 井上 毅: 鉄と镂, 76 (1990), p. 73

8 ) M. Nemoto: Metall. Trans. A, 8 (1977), p. 431

9 ) I. Zwell, L. A. Gorman and S. Weissmann: Trans. ASM, 59 (1966), p. 491

10) S. $W$. Thompson and P. R. Howell: Scr. Metall., 22 (1988), p. 1775 